Int. J. Dev. Biol. 52: 1113-1117 (2008)

doi: $10.1387 / \mathrm{ijdb} .0826161 \mathrm{~m}$

\title{
Expression of a retinal homeobox $(R x)$ gene during planarian regeneration
}

\author{
LINDA MANNINI, PAOLO DERI, JACOPO PICCHI and RENATA BATISTONI* \\ Dipartimento di Biologia, Università di Pisa, Italy
}

\begin{abstract}
Retinal homeobox $(R x)$ genes, with representatives in vertebrates and invertebrates, encode fundamental regulators of early eye and brain formation. Here we describe the spatiotemporal expression profile of a candidate planarian orthologue of $\boldsymbol{R x}$ during regeneration in Dugesia japonica and Schmidtea mediterranea. Although low levels of $R x$ transcripts were found throughout the body of intact planarians, high levels of $\boldsymbol{R x}$ expression were specific to regenerating tissue in both head and tail fragments. We also observed that $R x$ was never expressed in the simple rhabdomeric planarian eyes, supporting the notion that only formation of eyes that use the ciliary type of photoreceptors requires $R x$ function.
\end{abstract}

KEY WORDS: paired-class homeobox gene, $R x$, planarian, regeneration, eye

Rx paired-type homeobox transcription factors have been isolated in several vertebrate and invertebrate species (Arendt et al., 2004; Bailey et al., 2004 and references therein; D'Aniello et al., 2006). A growing body of evidence suggests that $R x$ genes, early expressed in the anterior neural plate, are essential for the proliferation and specification of retina progenitor cells in chordates. In invertebrates, such as Drosophila, $R x$ does not seem to play a similar role. In fact, Drosophila $R x$ is not required for the formation of the visual system, but only for brain and clypeus development (Davis etal., 2003). In addition, an $R$ xortholog of the annelid Platynereis has been found expressed in the ciliary photoreceptor cells of the brain, but not in the rhabdomeric photoreceptors of the larval and differentiating adult eyes (Arendt et al., 2004). Based on these observations, it has been proposed that an $R x$ ancestral function was related to the regulation of genes involved in brain development. During evolution, $R x$ genes became then essential for development of photoreceptors of ciliary type. No data are available on the function of $R x$ genes in a context different from the embryonic development, such as regeneration. Planarians (Platyhelminthes, Lophotrochozoa) offer a suitable model to investigate the role of $R x$ during regeneration. These organisms indeed can regenerate heads, including a complete brain, as well as other body parts in a short time, by virtue of the activity of adult stem cells, called neoblasts (Agata et al., 2006; Saló 2006; Sánchez Alvarado, 2006). Planarian brain consists of two anterior cephalic ganglia connected to two ventral nerve cords that run along the body (Cebrià, 2007). A pair of simple rhabdomeric eyes is generally located on its dorsal side. Despite the planarian central nervous system (CNS) seems quite simple at the morphological level, it possesses a functionally and molecularly complex structure (Cebrià, 2007 and references therein).

We have cloned and sequenced the cDNA of a planarian $R x$ homolog in Dugesia japonica (GI strain) and Schmidtea mediterranea (asexual strain). Animals were maintained in autoclaved stream water at $18^{\circ} \mathrm{C}$ and starved for two weeks before being used in the experiments. Fragments regenerating a head (anterior or cephalic regeneration) or a tail (posterior regeneration) were obtained by transverse amputation at the pharynx level. In these experimental conditions, regeneration was completed in about 2 weeks. A partial sequence of $D$. japonica $R x$ (DjRx), formerly named DjRax (accession number AB017633), was completed by SMART 5'RACE cDNA amplification kit (Clontech) and used for an in silico search in the $S$. mediterranea genome (Robb et al., 2008) to amplify the ortholog, SmedRx. Based on $S$. mediterranea genome analysis, we hypothesize the existence of a single-copy $R x$ gene in planarians. The full-length sequence of $D j R x$ and SmedRx contains an open reading frame

\footnotetext{
Abbreviations used in this paper: CNS, central nervous system; DjRx, Dugesia japonica retinal homeobox gene; SmedRx, Schmidtea mediterranea retinal homeobox gene; Rx, retinal homeobox.
}

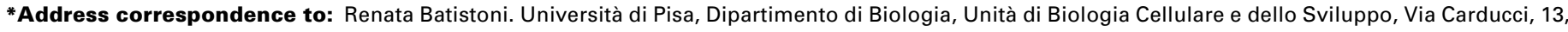
I-56010, Ghezzano (Pisa), Italy. Fax: +39-050-221-1495. e-mail: rbatistoni@biologia.unipi.it
}

Electronic Supplementary Material consisting of an audio PodCast is available for this article at: http://dx.doi.org/10.1387/ijdb.082616lm

Accepted: 6 June 2008; Published online: 14 August 2008. 


\begin{tabular}{|c|c|c|c|}
\hline & $\begin{array}{c}\text { Octa- } \\
\text { peptide }\end{array}$ & Homeodomain & OAR \\
\hline & & 60 & \\
\hline HSRX & HSIEAILG & HRRNRTTFTTYQLHELERAFEKSHYPDVYSREELAGKVNLPEVRVQVWFQNRRAKWRRQE & ADPRNSSIAALRLKAKEHIQA \\
\hline MMRX & $\ldots \ldots$ & 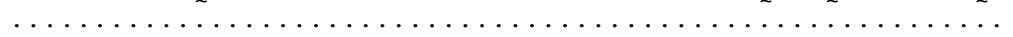 & 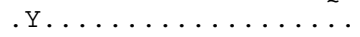 \\
\hline RNRX & $\ldots \ldots$ & 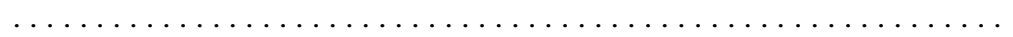 & 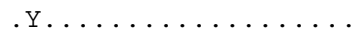 \\
\hline GGRX1 & ------- & 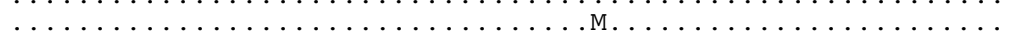 & V.Q.S...S.M....T \\
\hline GGRX2 & $\ldots \ldots$ & 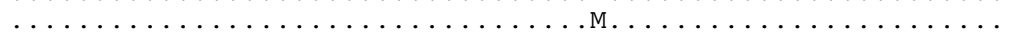 & G..T..S.M....S \\
\hline XLRXA & $\ldots \ldots$ & - & T...N.S..M.....F \\
\hline XLRXB & $\ldots \ldots$ & 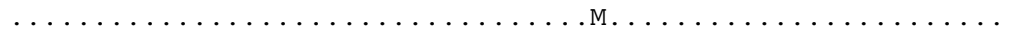 & I...N...S.M....S \\
\hline OLRX2 & -------- & 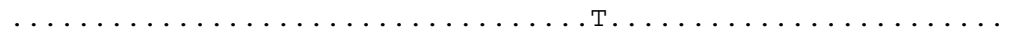 & D. ............-- \\
\hline DRRX1 & $\ldots$ DV . . &  & V.Q.S...........S \\
\hline DRRX2 & $\ldots D V \ldots$ & $\ldots \ldots \ldots \ldots \ldots \ldots \ldots \ldots \ldots$ & V. $-. S \ldots . . . . . . . S$ \\
\hline DRRX3 & $\ldots . . .$. & 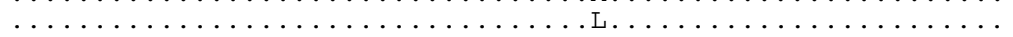 & $\ldots$...........S \\
\hline CIRX & YNE. VNNI & 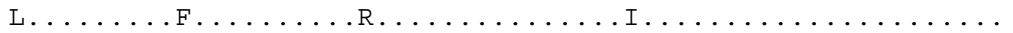 & NPD.SP.EKSFKRETA.EFRF \\
\hline ODRX & ------ & $\ldots \ldots \ldots$. . . . . . . . . . . . . . . . & 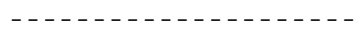 \\
\hline SKRX & $\ldots D \ldots$ & 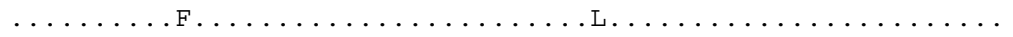 & N...S ..VS..M.....EN \\
\hline DMRX & .T.D... & 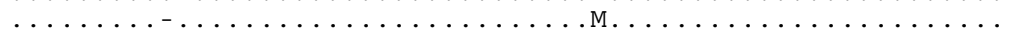 & T.M.SN..T.I....LDN \\
\hline PDRX & ------ &  & D...ST..VS..MR ...MK. \\
\hline DJRX & YN.DD . . . & ....M.IS. & SKDL . . NSKTCSIRTADNLNT \\
\hline SMEDRX & YN.DD . . & 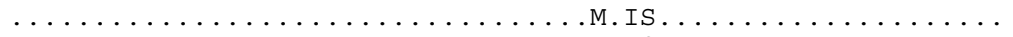 & SKDL . . NNKTCSIRSSDN. NG \\
\hline GTRX & ------- & 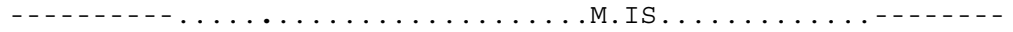 & ------------------- \\
\hline
\end{tabular}

Fig. 1. Comparison of predicted amino acid sequences among the octapeptide, homeodomain and OAR domain of DjRx and SmedRx and other Rx proteins. Identical amino acid residues are indicated by dots with respect to the HSRX: Homo sapiens RX (Q9Y2V3); incomplete sequences are indicated by hyphens. Sequences shown were obtained from the EMBL/ GenBank. CIRX: Ciona intestinalis RX (CAC34833); DRRX1: Danio rerio $R X 1$ (042356); DRRX2: Danio rerio $R X 2$ (042357); DRRX3: Danio rerio $R X 3$ (O42358); DMRX: Drosophila melanogaster $R X$ (CAA11241); DJRX: Dugesia japonica $R X$ (AM942442); GGRX1: Gallus gallus RX1 (O9PVY0); GGRX2: Gallus gallus RX2 (Q9PVX0); GTRX: Girardia tigrina RX (AY040121); MMRX: Mus musculus RX (NP038861); ODRX: Oikopleura dioica RX (AAW23065); OLRX2: Oryzias latipes RX2 (AJ007939); PDRX: Platynereis dumerili $R X$ (AAU20320); RNRX: Rattus norvegicus $R X$ (AAK07423); SKRX: Saccoglossus kowalevskii RX (AAP79282); SMEDRX: Schimdtea mediterranea $R X$ (AM942443); XLRX-A: Xenopus laevis $R X-A$ (O42201); XLRX-B: Xenopus laevis $R X-B$ (O42567).

(ORF) of $816 \mathrm{bp}$, encoding a protein of 272 amino acids with a paired (prd)-like homeodomain and an octapeptide motif (Fig. 1). DjRx and SmedRx appear almost identical at the amino acid level (90\% identity) and contain typical $\mathrm{Rx}$ hallmarks in the homeodomain: i) a glutamine residue is present at position $50-$ a site essential for the DNA-binding specificity - instead of the serine found in other members of the prd class, ii) they show methionine/glutamine exchange at position 36 , a feature fre-

A



C

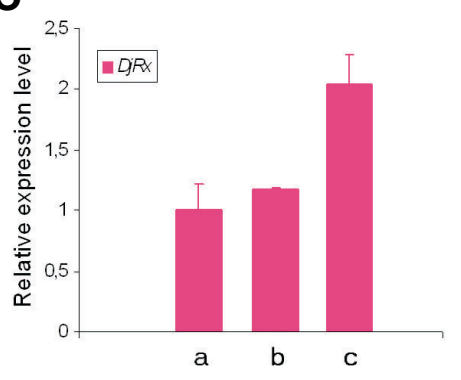

quently found in vertebrate and invertebrate Rx (Fig. 1). The serine/asparagine replacement observed at position 39 of the planarian $\mathrm{Rx}$ homeodomain probably represents a peculiarity of these organisms, shared only by Oikopleura dioica Rx (Edvardsen et al., 2005). Finally, planarian $\mathrm{Rx}$ do not show the 14 amino acid OAR domain identified in the C-terminal region of vertebrate and Drosophila $\mathrm{Rx}$, and considered important for transactivation (Furukawa et al., 1997).

Whole mount in situ hybridization was carried out to analyze the expression pattern of $R x$. Although no specific hybridization signal could be detected in intact planarians even after long staining, real time RT-PCR in $D$. japonicarevealed presence of $R x$ transcripts both in anterior and posterior regions of the planarian body (Fig. 2A). Considering the well-established localization of $R x$ transcripts to anterior domains in vertebrate and invertebrate species, it is striking that $R x$ can be expressed in a posterior part of the planarian body. The significance of this unusual expression is presently unclear, but it is tempting to speculate that distribution of $R x$ transcripts along the planarian body could be related to the amazing stem cell-based regenerative abilities of these animals, that can regenerate a complete individual from almost any body

Fig. 2. DjRx real time RT-PCR analysis of fragments from intact planarians. (A) Expression level of $D j R x$ in anterior $(H)$ and posterior $(T)$ body fragments obtained from planarians transected at the pharynx level. Expression levels are indicated in relative units assuming as unity the value of the anterior region. Each value is the mean \pm standard deviation of three independent samples, analyzed in duplicate. (B) Expression level of $\mathrm{DjRx}, 2$ days after $X$-ray ( $30 \mathrm{~Gy}$ ) irradiation. Expression levels are indicated in relative units, assuming the value of untreated specimens (c: control) as unity. Each value is the mean \pm standard deviation of three independent samples, done in duplicate. (C) Expression level of DjRx in cell fractions obtained by filtration through nylon meshes of $50 \mu \mathrm{m}$ (a), $20 \mu \mathrm{m}$ (b) and $8 \mu \mathrm{m}$ (c) pore size. Expression levels are indicated in relative units, assuming the value of $50 \mu \mathrm{m}$ nylon meshes as unity. Each value is the mean \pm standard deviation of three independent samples, analyzed in duplicate. 
fragment.

As in vertebrates $R x$ is required to control the proliferation of specific cell types (Bailey et al., 2004), we asked whether the planarian gene might have a role in regulating neoblast proliferation or their correct specification toward a specific fate. To test this hypothesis, we performed real time RT-PCR in intact animals sacrificed 2 days after a lethal dose of X-rays, a treatment that destroys neoblasts (Hayashi et al., 2006; Reddien et al., 2005; Rossi et al., 2007 and references therein; Salvetti et al., 2000). As shown in Fig. 2B, we observed that the elimination of neoblasts in irradiated animals did not reduce $R$ xexpression level with respect to the unirradiated controls, suggesting that $R x$ expression does not depend on the presence of proliferating cells. To extend our knowledge on the cells that express the planarian $R x$, we carried out real time RT-PCR using RNA obtained from dissociated cell fractions, selected for size by progressive filtering (Rossi et al., 2007; Salvetti et al., 2005) and found that $R x$ expression was preferentially detected in the fraction enriched in small cells (Fig. 2C). These data suggest that $R x$ plays a role in the specification of small cells, that, based on the size (Baguñà and Romero, 1981), could be differentiating/differentiated nerve cells.

Further real time RT-PCR experiments, undertaken during regeneration, revealed that $R x$ expression was upregulated both in tails regenerating a head (Fig. 3 ) and in heads regenerating a tail (Fig. 4). During anterior regeneration an increase in $R \times$ mRNA level was observed after 1 day of regeneration, reached a maximum around day 6 , and reduced progressively as regeneration proceeded (Fig. 3A). Whole mount in situ hybridization experiments visualized an expression profile that confirmed the specific activation of $R x$ transcripts. $R x$ expression pattern appeared very similar in $D$. japonica and $S$. mediterranea (Fig. 3B-K). By day 3 of regeneration, $R x$ transcripts could be detected in the blastema. As regeneration proceeded, $R x$ hybridization signal was detected in the medial and lateral brain regions, while it was never found in the rhabdomeric eye cells that were visualized by immunostaining with VC-1 antibody (Sakai et al., 2000) (Fig. 3L,M). This finding provides further confirmation that $R x$ function is required only for specification of photoreceptors of ciliary type (Saló et al., 2002). By using real time RT-PCR we noticed that the $R x$ expression level observed during tail regeneration was lower and slightly delayed in time (day 6 to day 10 , with a peak at day 8), with respect to that observed during head regeneration (Fig. 4A). At day $8, R x$ transcripts could be visualized in some cells that appeared spread in the regenerating tissue (Fig. 4B). We knocked down the $R x$ gene both in $D$. japonica and in $\mathcal{S}$. mediterranea by RNA interference (RNAi) and then investigated the effects at morphological and molecular level. Although small defects might be easily missed in this model, no significant alteration of the relative size of the blastema with respect to the water-injected controls was found by the analysis of the ratio between the blastema and the stump area using Nikon ACT-2U imaging software. Similarly, no defects could be visualized in the brain by whole mount in situ hybridization with the panneural marker synaptotagmin. To further identify possible effects of $R \times R$ RAi treatment, we also checked synaptotagminand DjOtxA (a marker specific for the brain region where the axons of photoreceptors project; Umesono et al., 1999) mRNA level by real time RT-PCR. Unfortunately, our real time RTPCR experiments did not reveal any significant variation of these transcripts after $R \times$ RNAi (data not shown). As $R \times R N A i$ did not
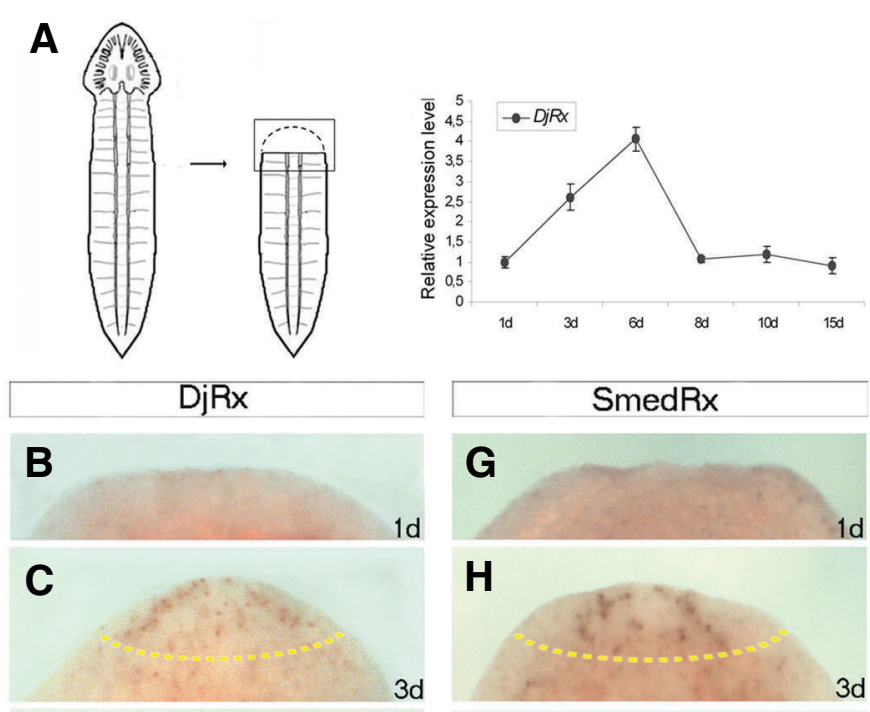

D
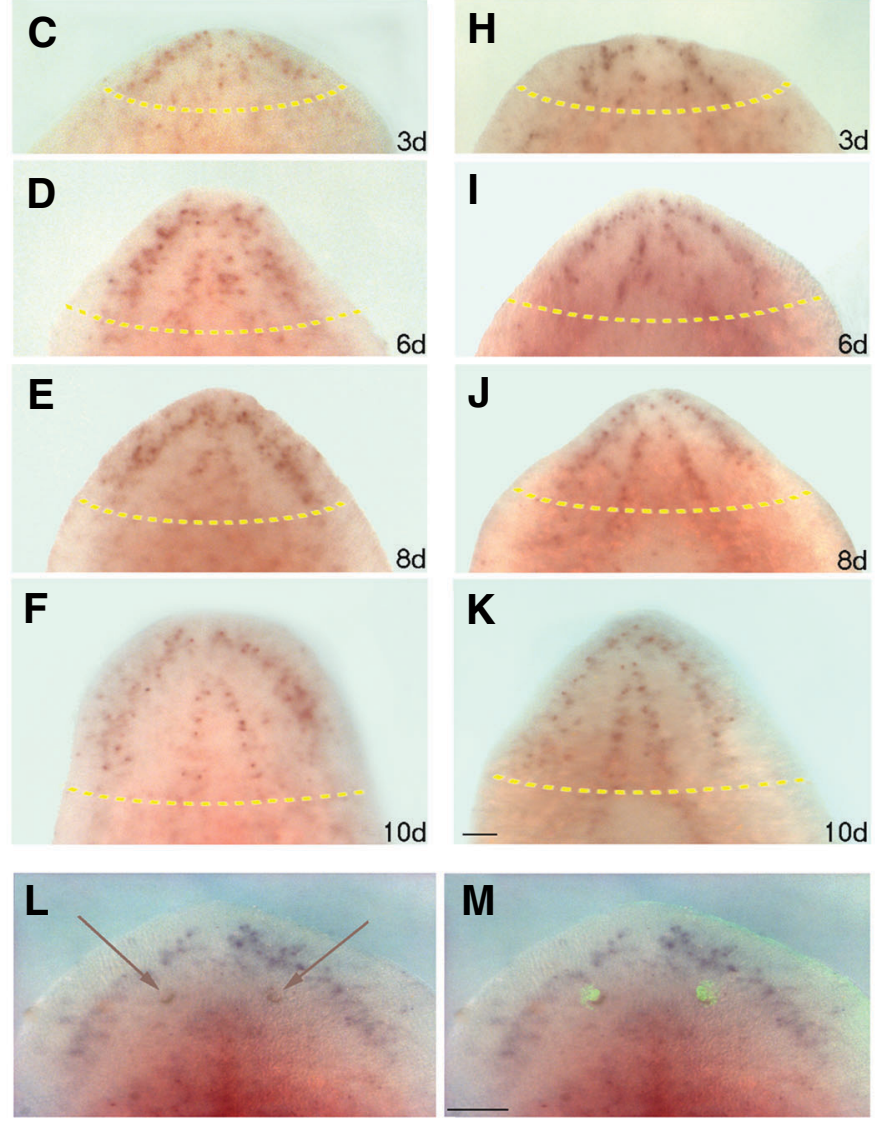

Fig. 3. $\boldsymbol{R} x$ expression during planarian head regeneration. (A) DjRx real time RT-PCR analysis. d, days of regeneration. CDNA samples derived from 4 small fragments including blastema and postblastema regions, boxed in the schematic drawing. Expression levels are indicated in relative units, assuming the value of one day-regenerating fragments as unity. Values are the mean of two independent experiments and error bars indicate standard deviation. (B-K) Ventral view of the regenerating fragments, as visualized by whole mount in situ hybridization with $\mathrm{DjRx}$ (B-F) and SmedRx (G-K). (L) Dorsal view of regenerating $\mathrm{D}$. japonica, as visualized by whole mount in situ hybridization with $\mathrm{DjR} \times \mathrm{x}$ days after amputation. The pigment cells of two small regenerating eyes can be detected as brown spots (brown arrows). (M) Immunostaining of whole mount in situ hybridization depicted in (L) with the photoreceptor-specific antibody VC-1 allows visualization of rhabdomeric eye cells. $d$, days of regeneration. Anterior is to the top. The dashed yellow line indicates the border between the regenerating region and the stump in C-F, H-K. Scale bars, $50 \mu \mathrm{m}$. 

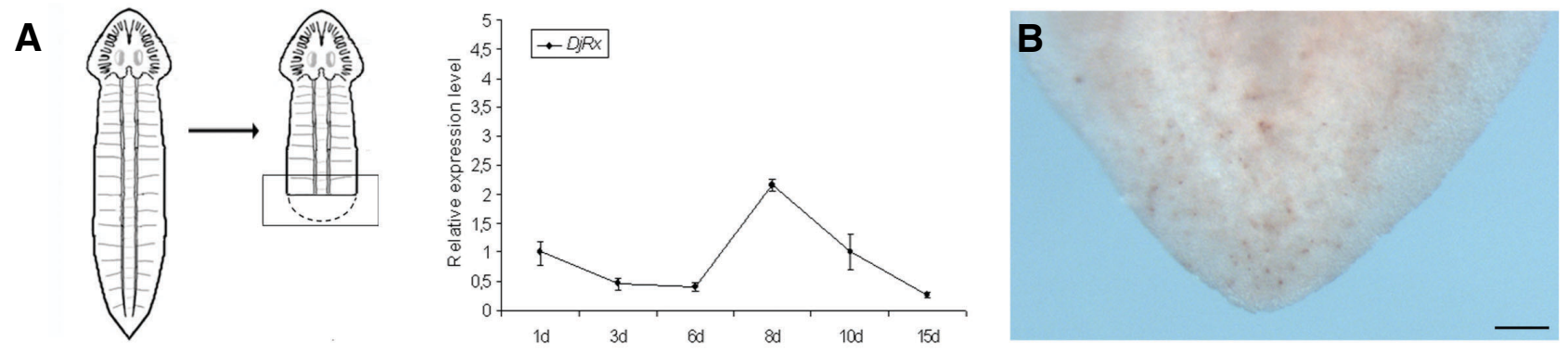

Fig. 4. Retinal homeobox (Rx) expression during planarian tail regeneration. (A) DjRx real time RT-PCR analysis. d, days of regeneration. cDNA samples derived from 4 small fragments including blastema and postblastema regions, boxed in the schematic drawing. Expression levels are indicated in relative units, assuming the value of one day-regenerating fragments as unity. Values are the mean of two independent experiments and error bars indicate standard deviation. (B) Dorsal view of a regenerating tail as visualized by whole mount in situ hybridization with DjRx 8 days after amputation. Scale bar, $50 \mu \mathrm{m}$.

produce any relevant defects, it is possible that other genes may compensate for $R x$ in planaria and we can only speculate that the Rx activity can be of importance for the correct specification of nerve cells during cephalic regeneration. The possibility that $R x$ activation observed during tail regeneration may play a role in neoblasts committed to a neural lineage remains to be explored.

\section{Experimental Procedures}

Whole mount in situ hybridization experiments were performed according to (Umesono et al., 1997; Umesono et al., 1999) with minor modifications (Nogi and Levin, 2005). Color development of the alkaline phosphate-coniugated anti-DIG-antibody was carried out with a mixture of BCIP/NBT (Sigma). To detect $R x$ hybridization signal in regenerating planarians chromogenic exposure was extended for approximately 8 hours. In contrast, no specific signal was visualized in intact animals also after 24-36 hours of substrate incubation. After whole mount in situhybridization, selected specimens were processed for immunostaining with the photoreceptorspecific antibody VC-1 (Sakai et al., 2000). Total RNA was extracted with the NucleoSpin RNAll kit (Macherey-Nagel) and was reverse-transcribed using Superscript First Strand Synthesis System (Invitrogen) from intact planarians, regenerating fragments, dissociated cells samples or irradiated planarians exposed to a lethal X-ray dose. Quantitative real time RT-PCR amplification was carried out with the ABI Prism 7000 Sequence Detection System (Applied Biosystems). PCR reactions were carried out using $20 \mathrm{ng}$ cDNA and TaqMan Universal PCR Master Mix (Applied Biosystems) following the manufacturer's protocol. DjEF2 was used as a normalizing gene to eliminate variation in cDNA concentration between the samples (Rossi et al., 2006; Rossi et al., 2007). Reactions were run in duplicate and 2 independent samples per experimental condition were used. Relative quantification of gene expression was performed using the comparative CT method as described in the ABI Prism 7700 Sequence Detection System User Bulletin No. 2.

DjRx: probe 5'CAGCTTCACTGATTGCCG 3',

forward 5'GTCCAAAAGACAGTTCAGAACAATCAC 3', reverse 5'TCCGGTGACGATTCTGTTTCG 3'.

\section{Acknowledgments}

We thank Dr. K. Agata for the in situ procedure, Dr. H. Orii for VC-1 antibody and Dr. C. Pugliesi for X-ray irradiation. We are indebted to members of Dr. Perata's lab for technical assistance with real time RT-PCR and to Dr. M.E. Isolani and members of Dr.
Saló lab for skilful advice with in silico analysis. This work was supported by funds from Programmi di Ricerca di Interesse Nazionale, MIUR, Italy.

\section{References}

AGATA, K., NAKAJIMA, E., FUNAYAMA, N., SHIBATA, N., SAITO, Y. and UMESONO, Y. (2006). Two different evolutionary origins of stem cell systems and their molecular basis. Semin Cell Dev Biol17: 503-509.

ARENDT, D., TESSMAR-RAIBLE, K., SNYMAN, H., DORRESTEIJN, A. W. and WITTBRODT, J. (2004). Ciliary photoreceptors with a vertebrate-type opsin in an invertebrate brain. Science 306: 869-871.

BAGUÑ̇̀, J. and ROMERO, R. (1981). Quantitative analysis of cell types during growth, degrowth and regeneration in the planarians Dugesia mediterranea and Dugesia tigrina. Hydrobiologia 84: 181-194.

BAILEY, T. J., EL-HODIRI, H., ZHANG, L., SHAH, R., MATHERS, P. H. and JAMRICH, M. (2004). Regulation of vertebrate eye development by rx genes. Int J Dev Bio/48: 761-770.

CEBRIÀ, F. (2007). Regenerating the central nervous system: how easy for planarians! Dev Genes Evol217: 733-748.

D'ANIELLO, S., D'ANIELLO, E., LOCASCIO, A., MEMOLI, A., CORRADO, M., RUSSO, M. T., ANIELLO, F., FUCCI, L., BROWN, E. R. and BRANNO, M. (2006). The ascidian homolog of the vertebrate homeobox gene $r x$ is essential for ocellus development and function. Differentiation 74: 222-234.

DAVIS, R. J., TAVSANLI, B. C., DITTRICH, C., WALLDORF, U. and MARDON, G (2003). Drosophila retinal homeobox (drx) is not required for establishment of the visual system, but is required for brain and clypeus development. Dev Biol 259: 272-287.

EDVARDSEN, R. B., SEO, H. C., JENSEN, M. F., MIALON, A., MIKHALEVA, J., BJORDAL, M., CARTRY, J., REINHARDT, R., WEISSENBACH, J., WINCKER, $P$. and D. CHORROUT (2005). Remodelling of the homeobox gene complement in the tunicate Oikopleura dioica. Curr Bio/15: R12-23.

FURUKAWA, T., KOZAK, C. A. and CEPKO, C. L. (1997). Rax, a novel paired-type homeobox gene, shows expression in the anterior neural fold and developing retina. Proc Natl Acad Sci USA 94: 3088-3093.

HAYASHI, T., ASAMI, M., HIGUCHI, S., SHIBATA, N. and AGATA, K. (2006). Isolation of planarian $\mathrm{x}$-ray-sensitive stem cells by fluorescence-activated cell sorting. Dev Growth Differ 48: 371-380.

NOGI, T. and LEVIN, M. (2005). Characterization of innexin gene expression and functional roles of gap-junctional communication in planarian regeneration. Dev Bio/287: 314-335.

REDDIEN, P. W., BERMANGE, A. L., MURFITT, K. J., JENNINGS, J. R. and SÁNCHEZ ALVARADO, A. (2005). Identification of genes needed for regeneration, stem cell function, and tissue homeostasis by systematic gene perturbation in planaria. Dev Cel/8: 635-649.

ROBB, S. M., ROSS, E. and ALVARADO, A. S. (2008). Smedgd: the Schmidtea mediterranea genome database. Nucleic Acids Res 36: D599-606. 
ROSSI, L., SALVETTI, A., LENA, A., BATISTONI, R., DERI, P., PUGLIESI, C., LORETI, E. and GREMIGNI, V. (2006). Djpiwi-1, a member of the paz-piwi gene family, defines a subpopulation of planarian stem cells. Dev Genes Evo/216: 335-346.

ROSSI, L., SALVETTI, A., MARINCOLA, F. M., LENA, A., DERI, P., MANNINI, L., BATISTONI, R., WANG, E. and GREMIGNI, V. (2007). Deciphering the molecular machinery of stem cells: a look at the neoblast gene expression profile. Genome Bio/8: R62.

SAKAI, F., AGATA, K., ORII, H. and WATANABE, K. (2000). Organization and regeneration ability of spontaneous supernumerary eyes in planarians - eye regeneration field and pathway selection by optic nerves. Zoo/Sci17: 375-381.

SALÓ, E. (2006). The power of regeneration and the stem-cell kingdom: freshwater planarians (platyhelminthes). Bioessays 28: 546-559.

SALÓ, E., PINEDA, D., MARSAL, M., GONZALEZ, J., GREMIGNI, V. and BATISTONI, R. (2002). Genetic network of the eye in platyhelminthes: expression and functional analysis of some players during planarian regeneration.
Gene 287: 67-74.

SALVETTI, A., ROSSI, L., DERI, P. and BATISTONI, R. (2000). An mcm2-related gene is expressed in proliferating cells of intact and regenerating planarians. Dev Dyn 218: 603-614.

SALVETTI, A., ROSSI, L., LENA, A., BATISTONI, R., DERI, P., RAINALDI, G., LOCCI, M. T., EVANGELISTA, M. and GREMIGNI, V. (2005). Djpum, a homologue of Drosophila pumilio, is essential to planarian stem cell maintenance. Development 132: 1863-1874.

SÁNCHEZ ALVARADO, A. (2006). Planarian regeneration: its end is its beginning Cel/ 124: 241-245

UMESONO, Y., WATANABE, K. and AGATA, K. (1997). A planarian orthopedia homolog is specifically expressed in the branch region of both the mature and regenerating brain. Dev Growth Differ39: 723-727.

UMESONO, Y., WATANABE, K. and AGATA, K. (1999). Distinct structural domains in the planarian brain defined by the expression of evolutionarily conserved homeobox genes. Dev Genes Evo/209: 31-39.

\section{Related, previously published Int. J. Dev. Biol. articles}

See our Special Issue Fertilization in honor of David Garbers and edited by P.M. Wassarman and V.D. Vacquier at: http://www.ijdb.ehu.es/web/contents.php?vol=52\&issue $=5 / 6$

See our Special Issue Evolution \& Development edited by Jaume Baguna and Jordi García-Fernández at: http://www.intjdevbiol.com/web/contents. php?vol=47\&issue=7-8

Planarian regeneration: achievements and future directions after 20 years of research Emili Saló, Josep F. Abril, Teresa Adell, Francesc Cebriá, Kay Eckelt, Enrique Fernández-Taboada, Mette Handberg-Thorsager, Marta Iglesias, M Dolores Molina and Gustavo Rodríguez-Esteban Int. J. Dev. Biol. (2008) 52: 2414-2414

From Planarians to Mammals - the many faces of regeneration Jerzy Moraczewski, Karolina Archacka, Edyta Brzoska, Maria-Anna Ciemerych, Iwona Grabowska, Katarzyna Janczyk-llach, Wladyslawa Streminska and Malgorzata Zimowska Int. J. Dev. Biol. (2008) 52: 219-227

Regulation of vertebrate eye development by $R x$ genes Travis J. Bailey, Heithem El-Hodiri, Li Zhang, Rina Shah, Peter H. Mathers and Milan Jamrich Int. J. Dev. Biol. (2004) 48: 761-770

Expression of DjXnp, a novel member of the SNF2-like ATP-dependent chromatin remodelling genes, in intact and regenerating planarians

Leonardo Rossi, Paolo Deri, Ilaria Andreoli, Vittorio Gremigni, Alessandra Salvetti and Renata Batistoni

Int. J. Dev. Biol. (2003) 47: 293-298

Retinal homeobox genes and the role of cell proliferation in cavefish eye degeneration

Allen G Strickler, Kuburat Famuditimi and William R Jeffery

Int. J. Dev. Biol. (2002) 46: 285-294

Disto-proximal regional determination and intercalary regeneration in planarians, revealed by retinoic acid induced disruption of regeneration R Romero and D Bueno Int. J. Dev. Biol. (2001) 45: 669-673

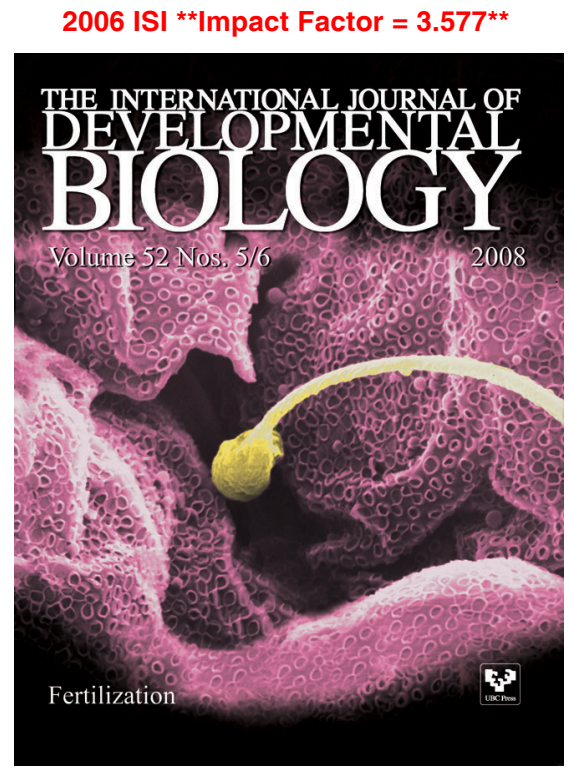

